\title{
Influence of Education on Poverty Intergenerational Transmission from the Perspective of Gender
}

\author{
Xiaowen $\mathrm{Xu}$ \\ School of Public Finance and Taxation, \\ Shandong University of Finance and Economics, \\ Jinan Shandong, 250014, China
}

\author{
Wanwan Feng \\ School of Public Administration and Policy, \\ Shandong University of Finance and Economics, \\ Jinan Shandong, 250014, China
}

\begin{abstract}
This work analyzed the current situation and particularity of female poverty and examined the influence of education on poverty intergenerational transmission for female. Since women have a more profound influence on children in the family, the education level of women has a reverse influence on poverty intergenerational transmission. The results showed that poverty thoughts can be avoided deriving by improving the education level of women and conducting ideological education so that women can be liberated from traditional family roles. In addition, poverty intergenerational transmission can be blocked by helping women get out of poverty in "intelligence" and "aspiration".
\end{abstract}

Keywords-Education; Female poverty; Intergenerational transmission; Gender equality

\section{INTRODUCTION}

Poverty has long been a major concern of the world, and eliminating poverty is also an arduous task of China for a long time. In 2020, China is going to realize the strategic layout of building a moderately prosperous society in all respects, which requires winning the tough battle of poverty alleviation. According to current national poverty standards in rural areas (the price level in 2010 was 2300 yuan per person per year), by 2016, there were 43.35 million rural poverty people in China, and a total of 55.64 million people got out of poverty compared with 2012, showing that poverty alleviation has achieved remarkable results in China. According to the gender grouping, there is no significant difference in poverty incidence between the female group and male group in 2016. However, rural women are more special than men in the poverty population. Under the same condition, the incidence of female poverty is higher than that of males since the phenomenon of gender discrimination is more obvious in terms of poverty. Moreover, due to the impact of educational opportunity cost and future income uncertainty, family poverty can hinder future generations from receiving higher levels of education, which in turn leads to persistent poverty and difficulty to jump out of the poverty trap (Zou Wei et al., 2014) [1].

Family intergenerational relations usually play an extremely important role in people's lives. In traditional Chinese thought, women are generally subordinate in the family. The traditional idea of "male work outside and female

Fund Project: Key Project of Social Science Planning in Shandong Province - "Research on Fiscal and Taxation Policies to Promote the Development of Green Economy in Shandong Province" (18BJJJ07). work inside" is particularly serious in poverty areas. The longstanding phenomenon of gender inequality in the labor market has made many families more inclined to invest in male education based on the principle of utility maximization. Women in poor families are significantly less likely to receive education than others, so they enter family roles earlier in adulthood. Under this traditional social and cultural background, women take more care of their children and have a greater impact on their children's growth process. According to the China Family Development Report in 2015, about $47.6 \%$ of caregivers for children (0-5 years old) are mothers and $38 \%$ are grandparents. Based on CFPS data and empirical views, Zou Hong et al. (2018) verified that even in families that choose to care for the next generation, more female elderly people are responsible to take care of their offspring [2]. CHNS data can be used to identify the poverty situation of fathers and children as well as mothers and children in two generations by matching the kinship of respondents, and then the probability of each situation can be calculated to reflect the intergenerational flow. The result shows that regardless of the dynamic trend or the urban-rural distribution, the intergenerational transmission probability of mothers is slightly higher than that of fathers (Lu Shengfeng et al., 2016) [3]. In addition, Zou Wei et al. (2019) estimated that although women are less likely to be educated than men, mothers' influence on the educational level of future generations, especially the level of receiving compulsory education or above, is higher than that of fathers, and this effect has intergenerational transmission.

Paying attention to female poverty and its intergenerational transmission can better understand the nature of poverty. Improving the education level of mothers in a family can promote investment of human capital, help poor families to get rid of persistent poverty and reduce the phenomenon of returning to poverty.

\section{Poverty FROM THE PeRsPective OF GENDER}

\section{A. The current situation of female poverty}

There are more and more women involved in the labor force, and the male to female ratio is shrinking in the labor market. The sixth census data also shows that the gap in employment between male and female at different ages is small. On the surface, the proportion of female employment in China 
is already high, but according to the Human Development Report in 2011 issued by the United Nations Development Programme, China ranks 35th out of 187 countries in the world if it is ranked by gender inequality index, which is higher than the United States (47th). Gender inequality caused by traditional thoughts of favoring sons over daughters in most areas has largely deprived women of their rights. Especially in most rural areas, men go out to work and women are more responsible for heavy farming responsibilities, leading to low income, life without security and low level of education. The World Bank pointed out that the feminization of agricultural production means the feminization of poverty in the Center for Gender and Refugee Studies of China in 2002.

Poverty is not "homogeneous" in a family. Women have fewer resources in the family than men and have a higher chance of falling into poverty. The status of women in rural and remote areas of poor families, resources obtained within the family and physical health are more influenced by the traditional thoughts of favoring sons to daughters. When resource within a family is limited, men are the priority of resource earners. Since women are more engaged in household labor and some reproduction activities without financial rewards, their negotiating ability in family resource allocation is weakened. Using a single household as a unit for measuring poverty ignores the particularity of female poverty by admitting that women and men have equal opportunities falling into poverty.

Female poverty is not only manifested by material poverty caused by the uneven distribution of resources within the family, but also by cultural poverty. Poor families have a lower willingness to invest in education since poor households have a weaker ability to resist risks. Any investment risk may make the already distressed family worse. The time span of investment return for education is longer for low-income families, and results are unpredictable. The phenomenon of gender discrimination in the labor market has led to more investment of limited resources within the family in men, which is more significant in families with more children. In rural areas, the phenomenon of female cultural poverty is more common. In 2016, the proportion of women with high-school education or above in permanent female labor force of rural poverty areas in China was $7.9 \%$, which was $7.1 \%$ lower than that of male labor; the proportion of primary-school education or below was $51.5 \%$, which was $18.4 \%$ higher than that of male labor. The female labor force in rural poverty areas is generally less educated than the male labor force, as shown in Fig. 1.

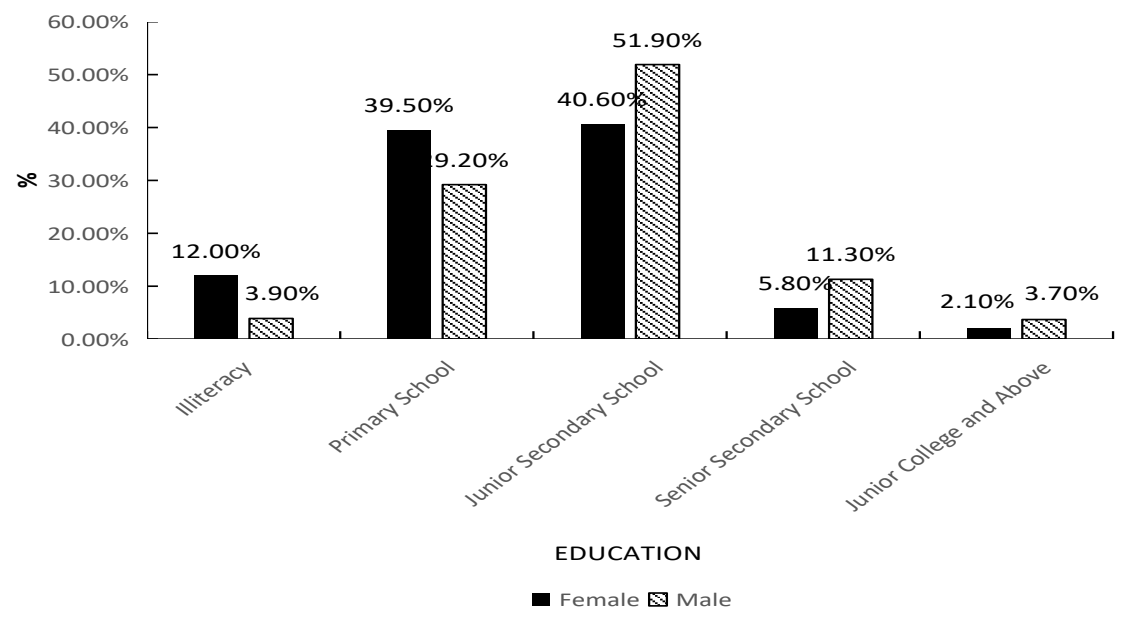

Fig. 1. Educational level distribution of the labor force in poor areas in 2016

\section{B. The particularity of female poverty}

Female poverty has its own particularity. On the one hand, since women are more responsible for housework and some agricultural activities in the family, female poverty is less likely to cause concern in the family and it has certain concealment. On the other hand, female poverty is fragile. The vulnerability of female poverty means that women are more vulnerable in social, economic and cultural aspects. At the same time, under the background of men tend to go out to make money, women have their own particularity in nurturing and educating their offspring. Their psychological endurance, self-confidence and other abilities are likely to weaken by their lack of nutrition, medical treatment and education. The impact on their children is that their social competitiveness and self- improvement ability are weakened after their children become adults, and children can even occur unhealthy psychology. The role of women as mothers has a far-reaching impact on children, and their roles of intergenerational transmission in poverty cannot be ignored.

\section{IMPACT OF EDUCATION ON INTERGENERATIONAL TRANSMISSION OF FEMALE POVERTY}

\section{A. Definition of intergenerational transmission of poverty}

The issue of female poverty has been concerned by many disciplines since the 1960s and 1970s. From the perspective of intergenerational transmission, the nature of poverty can be better understood, so as to reduce the incidence of povertyreturning. The concept of intergenerational transmission was 
proposed in the 1960s when American economists studied long-term poverty. Later, based on conducting practical research on the underlying class, many scholars evolved the concept of "poverty intergenerational transmission" from the research paradigm of sociological intergenerational mobility. For example, Oscar Lewis, an early representative of the theory of intergenerational poverty, first proposed the concept of cultural poverty and believed that poverty intergenerational transmission is characterized by economic and psychological characteristics with various interactions. Moore K (2000) believes that family poverty is the decisive factor for children to work to increase their income [5]. Parents and family structure are significantly associated with the use of child labor Children born in poor families are more likely to fall into poverty after growing up than those in non-poor families, since long-standing poverty has caused intergenerational transmission of poverty.

Nowadays, the definition of poverty intergenerational transmission has become more consistent, that is, the poverty status of the family, as well as related conditions and factors that lead to poverty, are transmitted from parents to children within the family, causing children to experience the same situation as their parents in adulthood. They will inherit the poverty and disadvantages of parents, and then pass on poverty and unfavorable factors to later generations, causing a vicious circle of genetic chains.

\section{B. The role of education in the intergenerational transmission of female poverty}

1) The impact of education on female social status

The intergenerational transmission of female poverty is reflected in the transmission of the mother's social status and education level in future generations. At present, most of the poor women in China are employed in low wages or are unemployed outside the employment relationship, and their social status is low. Although urbanization has broken the traditional Chinese dual social system barriers, more men go out to work in rural families, resulting in the unique "leftbehind women" and "left-behind children" in rural areas. In rural areas, nearly $80 \%$ of women work in the primary industry. Women are responsible for producing labor and educating children, but they are unable to obtain social status. Even if the next generation becomes parents, their social status is still low, causing a vicious circle of intergenerational transmission. Improving the education level of mothers will increase their ability to bargain in the family and increase the opportunity for girls' education, which will have a positive effect on eliminating the gender differences in the education of future generations and thus increasing the status of women and blocking the intergenerational transmission of poverty.

\section{2) Education helps to block the derivation of poverty} thoughts

Since fathers are less involved in the education of "leftbehind children", mothers are mainly involved in the education of children. Even in poor families without "left-behind women" and "left-behind children", parents are busier with their livelihood and neglect their children's education. The lack of cultural capital caused by the weak economic foundation of poor families has caused the failure of children's education.
The lack of education support from previous generations and "regurgitation-feeding" of the "poor second generation" have formed the intergenerational transmission of poor subcultures. Especially in rural areas of China, the traditional thought of "men work outside and women work inside" leads to more "left-behind women". As a major participant in the growth and education of children, mothers will make the traditional backward thoughts continue on their children. The growing process of children is influenced by their mothers' words and deeds, leading to the derivation of poverty thoughts. Lundborg $P$ et al (2011) discover that well-educated parents can give children a better education, and mothers' education is more important for children's cognitive and non-cognitive development [6].

3) Education helps to improve the health condition of offspring

It seems that women are responsible for the income and expenditure of the family and have the right to distribute resources within the family. However, women who are less educated and deeply influenced by traditional thoughts, especially poor women, often sacrifice their own needs to meet the needs of their children and spouses, so that women's nutritional needs, physical and mental health are correspondingly hurt. Huo Xuan (2015) calls this phenomenon as female "self-poverty" 8. The "self-sacrifice" of women in the family seems to only damage their health, but it actually affects the health of their children (fetuses). The mothers' educational level will subtly affect non-genetic factors related to their children's weight, such as mothers' nutrition, health level and prenatal status. Studies have shown that mothers' level of education has a positive impact on the birth weight of the offspring. For every additional year of mothers' education, the probability of low birth weight children and abortion are reduced by $1 \%$ Currie \& Moretti (2003) [7]. The psychological stress and anxiety faced by "left-behind mothers" will also lead to intergenerational transmission. The living conditions encountered by poor women will make the next generations repeat this situation. In order to better block the intergenerational transmission of female poverty, it is necessary to stop the intergenerational transmission of poverty at the starting point of life. In general, mothers with high levels of education receive higher social status and income, have better ability to obtain information and resist pressure, and dominant more corresponding disposable income in children's education and nutrition, which can provide more growth resources for children and create a better growth environment.

\section{CONCLUSION}

The problem of intergenerational transmission of female poverty in China has become increasingly serious, and it has gradually become more stable and institutionalized, which is the top priority of China's targeted poverty alleviation. In the past, when indicators for poverty measurement were not gender-specific, the poverty situation of female groups was more easily overlooked. Even after considering gender differences and then measuring poverty, there are still some institutional obstacles in the actual operation. The impact of education is long-lasting, and it is even greater between generations than across generations. In order to block the 
intergenerational transmission of female poverty, it is necessary to pay more attention to improve the educational level of poor women through carrying out ideological education, transforming traditional gender concepts, and avoiding the derivation of poverty thoughts. The level of education and child care are the main factors affecting women's entry into the labor market. Increasing investment in education and child care can reduce the family pressure of poor women, allowing women to liberate from traditional family roles and realizing poverty alleviation in terms of "intelligence" and "aspiration". The improvement of mothers' ability will be transferred to the next generation to a certain extent, thereby reducing the cost of education and avoiding the persistence of poverty.

The problem of female poverty in China is not only a historical issue but also a social reality. It is necessary to take measures to promote female poverty alleviation and avoid the phenomenon of "poverty returning". Since the level of education in the society can be artificially interfered and controlled, which has been confirmed by China's compulsory education popularization, the intergenerational transmission of poverty can be blocked by improving female education level and achieving inclusive growth.

\section{REFERENCES}

[1] Zou Wei, Zheng Hao. Why Don't Children From Poor Families Read Books: Risk, Intergenerational Transmission of Human Capital and Poverty Trap [J]. Economic Perspectives, 2014 (06): 16 - 31.

[2] Zou Hong, Peng Zhengcheng, Luan Bingjiang. Intergenerational Care and Female Labour Supply - Research on the Paradox of Comprehensive Two-child and Delayed Retirement From the Perspective of Care, 2018(07):37 - 52.

[3] Lu Shengfeng, Pan Xingyu. Intergenerational Transmission of Poverty Among Chinese Residents: Spatial Distribution, Dynamic Trend and Empirical Measurement [J]. Economic Science, 2016(06): 5 - 19.

[4] Zou Wei, Ma Zhanli. Family Background, Intergenerational Transmission and Educational Inequality [J]. China's Industrial Economy, 2019(02): 80 - 98.

[5] Moore K. Supporting Children in Their Working Lives: Obstacles and Opportunities Within the International Policy Environment[J]. Journal of International Development: The Journal of the Development Studies Association, 2000, 12(4): 531 - 548.

[6] Lundborg P, Nordin M, Dan O R. The Intergenerational Transmission of Human Capital: the Role of Skills and Health[J]. Journal of Population Economics, 2011, 31(4):1 - 31.

[7] Currie \& Moretti(2003), "Mother's Education and the Intergenerational Transmission of Human Capital", The Quarterly Journal of Economics, 118(4): 1495 - 1532. 